Editor's Note: These short reviews of recent JNeurosci articles, written exclusively by students or postdoctoral fellows, summarize the important findings of the paper and provide additional insight and commentary. If the authors of the highlighted article have written a response to the Journal Club, the response can be found by viewing the Journal Club at www.jneurosci.org. For more information on the format, review process, and purpose of Journal Club articles, please see http://jneurosci.org/content/ preparing-manuscript\#journalclub.

\title{
Activity-Dependent Myelination Shapes Conduction Velocity
}

\author{
-Benayahu Elbaz \\ Department of Neurology, Center for Peripheral Neuropathy, University of Chicago, Chicago, Illinois 60637 \\ Review of Etxeberria et al.
}

Myelin ensheaths and insulates axons, allowing efficient propagation of action potentials. Myelin is formed by oligodendrocytes in the CNS and Schwann cells in the PNS. During CNS development, most oligodendrocyte progenitor cells originate in the ventricular zone and migrate along vasculature to their target axons where they terminally differentiate into mature oligodendrocytes. As mature oligodendrocytes, they begin expressing myelin transcripts, produce myelin, wrap axons, and provide metabolic support to the axons (Simons and Nave, 2015; Tsai et al., 2016).

Although most oligodendrocyte precursor cells mature in the early postnatal period, oligodendrocyte progenitor cells continue to proliferate and generate mature oligodendrocytes throughout life. To study the role of these adult-born oligodendrocytes, Young et al. (2013) used Pdgfra-CreER:tau-mGFP mice in which administration of tamoxifen stimulates Cre-Lox recombination in oligodendrocyte progenitor cells that, upon differentiation, express mGFP to reveal myelin morphology. They found that adult-born oligodendrocytes remodel myelin (Young et al., 2013). The proliferative rate of oligodendrocyte progenitor cells was significantly different in distinct brain regions, suggesting that local environment strongly affects the mitotic capacity of these cells, but the cues responsible remained unknown.

\footnotetext{
Received Aug. 29, 2016; revised 0ct. 7, 2016; accepted 0ct. 11, 2016.

I thank Maria Traka for valuable discussions and comments.

The authors declare no competing financial interests.

Correspondence should be addressed to Dr. Benayahu Elbaz, Department of Neurology, University of Chicago Center for Peripheral Neuropathy, University of Chicago, Chicago, IL 60637. E-mail: belbaz@neurology.bsd.uchicago.edu.

DOI:10.1523/JNEUROSCI.2727-16.2016

Copyright $\odot 2016$ the authors $\quad 0270-6474 / 16 / 3611585-02 \$ 15.00 / 0$
}

A recent report (Etxeberria et al., 2016) investigated neuronal cues that regulate proliferation of oligodendrocyte progenitor cells by studying the effect of visual experience on myelin. They generated NG2-CreER:tau-mGFP mice in which administration of tamoxifen results in mGFP expression in newly formed oligodendrocytes and found that monocular visual deprivation increased the differentiation of oligodendrocyte progenitor cells into mature oligodendrocytes without altering proliferation. Increased oligodendrogenesis was not accompanied by changes in the number of myelinated axons, myelin thickness, or changes in the total number or size of target axons. Monocular deprivation, however, resulted in decreased internodal length along retinal ganglion cell axons, suggesting that visual experience influences the structure of myelinated fibers. Because internodal length is directly linked to action potential conduction velocity (Wu et al., 2012), Etxeberria et al. (2016) tested the effect of monocular deprivation on conduction velocity and found that visual experience modulates action potential conduction properties.

Myelination of open-eye axons was affected in the ipsilateral optic tract, where most axons were from the deprived eye, suggesting that myelination of individual axons is sensitive to the activity in the surrounding axons. The environmental effect of surrounding axons suggested that a secreted factor controlled this activity-dependent myelination. Because glutamate is the main neurotransmitter used by retinal ganglion cells and because both myelinated and unmyelinated axons release glutamate along the axon upon spiking (Kukley et al., 2007; Ziskin et al., 2007; Wake et al., 2011), Etxe- berria et al. (2016) conditionally ablated the vglut2 gene, which encodes the protein responsible for glutamate uptake into vesicles, in ganglion cells. This decreased glutamate release from retinal axons, thus mimicking sensory deprivation. Consistent with the findings from the monocular deprivation experiment, VGlut2KO mice displayed increased oligodendrogenesis and reduced internodal length.

This demonstration that axonal glutamatergic cues influence the structure of myelin strongly suggests that oligodendrocytes sense glutamate. Indeed, oligodendrocytes express a variety of glutamate receptors, including NMDA receptors, but the role of these receptors in the cells has been ambiguous for several reasons. Previous studies (De Biase et al., 2011; Guo et al., 2012) determined that NMDA receptors are not necessary for myelination. Indeed, oligodendrocytes can myelinate PFA-fixed, dead neurons or plastic nanofibers (S. Lee et al., 2012), demonstrating that glutamatergic cues are not necessary for myelination. Similarly, oligodendrocytes have been shown to carry an intrinsic, axon-independent property to respond to axon diameter (Bechler et al., 2015), further suggesting that axonal cues are not necessary for myelination. Nonetheless, a recent report found that NMDA receptors do play a crucial role in oligodendrocytes. Saab et al. (2016) ablated NMDA receptors from oligodendrocyte lineage cells; and although NMDA receptors were not necessary for myelination per se, they were used by oligodendrocytes to sense the electrical activity of the surrounding axons and adjust their metabolic support to the axons accordingly (Saab et al., 2016). 
Oligodendrocytes are metabolically coupled to axons. It has been suggested that, in this metabolic coupling, oligodendrocytes supply lactate to axons through the lactate transporter MCT1 (Fünfschilling et al., 2012; Y. Lee et al., 2012). Oligodendroglial NMDA receptors regulate the trafficking of the glucose transporter GLUT1 to the membrane and thereby govern oligodendrocyte glucose import. Using a glucose sensor in transfected oligodendrocytes, Saab et al. (2016) found that activation of NMDA receptors significantly increased the glucose signal in oligodendrocytes, and this was abolished by addition of D-AP5, which blocks NMDA receptor binding sites. These data suggest that glutamatergic neuronal cues activate oligodendrocyte NMDA receptors, which in turn control oligodendrocyte glucose uptake and glycolysis. Increased glycolysis could conceivably increase lactate shuttling to axons, thus supporting of axonal energy metabolism.

Importantly, these experiments in which either NMDA receptors or glutamate release were manipulated yielded similar results. Etxeberria et al. (2016) decreased glutamate release by conditionally ablating the vglut2 gene from retinal ganglion cells and found that this reduced conduction velocity in the affected nerves. Likewise, Saab et al. (2016) ablated NMDA receptors from oligodendrocyte lineage cells and found reduced conduction velocity in the affected nerves. In addition, Saab et al. (2016) found that lactate could replace glucose as an energy source for the affected nerve and restore conduction, independent of prior NMDA receptor signaling. Further investigation of oligodendrocyte glucose uptake and lactate shuttling to axons using the Islet1-cre ${ }^{+-}$VGlut $^{\text {fl/fl }}$ mice used by Etxeberria et al. (2016) would thus likely yield noteworthy results. Based on the results of Saab et al. (2016), one may anticipate that decreased glutamate release by conditionally ablating the vglut2 gene will lead to reduced glucose uptake by oligodendrocytes, which in turn, will result in reduced metabolic support from oligodendrocytes to axons.

Interestingly, Etxeberria et al. (2016) found that monocular deprivation altered internodal length along retinal axons without changing myelin thickness. ERK1/ERK2 MAPK signaling has been shown to control myelin thickness (Ishii et al., 2012), but the molecular mechanisms controlling internodal length are poorly understood (Bechler et al., 2015). Because myelin production relies heavily on glucose import to oligodendrocytes as a source of carbon for lipid metabolism (Rinholm et al., 2011), the reduced internodal length observed by Etxeberria et al. (2016) may suggest that proper formation of internodes relies on proper glucose supply to oligodendrocytes, governed by glutamate released from axons.

Nervous system function and plasticity are governed by synaptogenesis, synaptic elimination, and synaptic plasticity. In addition, nervous system plasticity is highly dependent on precise conduction velocity between different nodes of neural circuits (Dan and Poo, 2006). Conduction velocities range widely across axons. Genetic instruction alone cannot explain how conduction velocity in neuronal circuits, which comprise billions of axons, is so tightly controlled (Fields, 2015). Etxeberria et al. (2016) demonstrated that the length of myelin internodes is modified by experiencedependent activity, resulting in alterations in action potential conduction velocity. This finding suggests that variations in conduction velocity that provide a degree of plasticity are controlled not only genetically, but are also established in accordance to local activity. Therefore, the study by Etxeberria et al. (2016) deepens our understanding of activity-dependent myelination as a new mechanism that controls conduction velocity and may suggest that activity-dependent myelination has an important role in nervous system plasticity.

\section{References}

Bechler ME, Byrne L, Ffrench-Constant C (2015) CNS myelin sheath lengths are an intrinsic property of oligodendrocytes. Curr Biol 25: 2411-2416. CrossRef Medline

Dan Y, Poo MM (2006) Spike timing-dependent plasticity: from synapse to perception. Physiol Rev 86:1033-1048. CrossRef Medline

De Biase LM, Kang SH, Baxi EG, Fukaya M, Pucak ML, Mishina M, Calabresi PA, Bergles DE (2011) NMDA receptor signaling in oligodendrocyte progenitors is not required for oligodendrogenesis and myelination. J Neurosci 31:12650-12662. CrossRef Medline

Etxeberria A, Hokanson KC, Dao DQ, Mayoral SR, Mei F, Redmond SA, Ullian EM, Chan JR (2016) Dynamic modulation of myelination in response to visual stimuli alters optic nerve conduction velocity. J Neurosci 36:69376948. CrossRef Medline

Fields RD (2015) A new mechanism of nervous system plasticity: activity-dependent myelination. Nat Rev Neurosci 16:756-767. CrossRef Medline

Fünfschilling U, Supplie LM, Mahad D, Boretius S, Saab AS, Edgar J, Brinkmann BG, Kassmann CM, Tzvetanova ID, Möbius W, Diaz F, Meijer D, Suter U, Hamprecht B, Sereda MW, Moraes CT, Frahm J, Goebbels S, Nave KA (2012) Glycolytic oligodendrocytes maintain myelin and long-term axonal integrity. Nature 485:517-521. CrossRef Medline

Guo F, Maeda Y, Ko EM, Delgado M, Horiuchi M,
Soulika A, Miers L, Burns T, Itoh T, Shen H, Lee E, Sohn J, Pleasure D (2012) Disruption of NMDA receptors in oligodendroglial lineage cells does not alter their susceptibility to experimental autoimmune encephalomyelitis or their normal development. J Neurosci 32: 639-645. CrossRef Medline

Ishii A, Fyffe-Maricich SL, Furusho M, Miller RH, Bansal R (2012) ERK1/ERK2 MAPK signaling is required to increase myelin thickness independent of oligodendrocyte differentiation and initiation of myelination. J Neurosci 32:8855-8864. CrossRef Medline

Kukley M, Capetillo-Zarate E, Dietrich D (2007) Vesicular glutamate release from axons in white matter. Nat Neurosci 10: 311-320. CrossRef Medline

Lee S, Leach MK, Redmond SA, Chong SY, Mellon SH, Tuck SJ, Feng ZQ, Corey JM, Chan JR (2012) A culture system to study oligodendrocyte myelination processes using engineered nanofibers. Nat Methods 9:917-922. CrossRef Medline

Lee Y, Morrison BM, Li Y, Lengacher S, Farah MH, Hoffman PN, Liu Y, Tsingalia A, Jin L, Zhang PW, Pellerin L, Magistretti PJ, Rothstein JD (2012) Oligodendroglia metabolically support axons and contribute to neurodegeneration. Nature 487:443-448. CrossRef Medline

Rinholm JE, Hamilton NB, Kessaris N, Richardson WD, Bergersen LH, Attwell D (2011) Regulation of oligodendrocyte development and myelination by glucose and lactate. J Neurosci 31:538-548. CrossRef Medline

Saab AS, Tzvetavona ID, Trevisiol A, Baltan S, Dibaj P, Kusch K, Möbius W, Goetze B, Jahn HM, Huang W, Steffens H, Schomburg ED, Pérez-Samartín A, Pérez-Cerdá F, Bakhtiari D, Matute C, Löwel S, Griesinger C, Hirrlinger J, Kirchhoff F, et al. (2016) Oligodendroglial NMDA receptors regulate glucose import and axonal energy metabolism. Neuron 91:119132. CrossRef Medline

Simons M, Nave KA (2015) Oligodendrocytes: myelination and axonal support. Cold Spring Harb Perspect Biol 8:a020479. CrossRef Medline

Tsai HH, Niu J, Munji R, Davalos D, Chang J, Zhang H, Tien AC, Kuo CJ, Chan JR, Daneman R, Fancy SP (2016) Oligodendrocyte precursors migrate along vasculature in the developing nervous system. Science 351:379384. CrossRef Medline

Wake H, Lee PR, Fields RD (2011) Control of local protein synthesis and initial events in myelination by action potentials. Science 333: 1647-1651. CrossRef Medline

Wu LM, Williams A, Delaney A, Sherman DL, Brophy PJ (2012) Increasing internodal distance in myelinated nerves accelerates nerve conduction to a flat maximum. Curr Biol 22: 1957-1961. CrossRef Medline

Young KM, Psachoulia K, Tripathi RB, Dunn SJ, Cossell L, Attwell D, Tohyama K, Richardson WD (2013) Oligodendrocyte dynamics in the healthy adult CNS: evidence for myelin remodeling. Neuron 77:873-885. CrossRef Medline

Ziskin JL, Nishiyama A, Rubio M, Fukaya M, Bergles DE (2007) Vesicular release of glutamate from unmyelinated axons in white matter. Nat Neurosci 10:321-330. CrossRef Medline 